\title{
Correction to: Neoadjuvant chemoradiotherapy delivered with helical tomotherapy under daily image guidance for rectal cancer patients: efficacy and safety in a large, multi-institutional series
}

\author{
Berardino De Bari ${ }^{1,2}$ (1) Alessandra Franzetti-Pellanda ${ }^{3} \cdot$ Asma Saidi $^{1} \cdot$ Maira Biggiogero $^{3} \cdot$ Dieter Hahnloser $^{4}$. \\ Michael Montemurro ${ }^{5}$ Jean Bourhis ${ }^{1} \cdot$ Michele Zeverino $^{6} \cdot$ Mahmut Ozsahin $^{1}$
}

Published online: 14 June 2019

(c) The Author(s) 2019

\section{Correction to: Journal of Cancer Research and Clinical Oncology (2019) 145:1075-1084 https://doi.org/10.1007/s00432-019-02881-8}

The article "Neoadjuvant chemoradiotherapy delivered with helical tomotherapy under daily image guidance for rectal cancer patients: efficacy and safety in a large, multi-institutional series", written by Berardino De Bari, was originally published Online First without open access. After publication in volume 145, issue 4, pages 1075-1084 the author decided to opt for Open Choice and to make the article an Open Access publication. Therefore, the copyright of the article has been changed to $($ ) The Author(s) 2019 and the article is forthwith distributed under the terms of the Creative Commons Attribution 4.0 International License (http://creativecommons.org/licenses/by/4.0/),

The original article can be found online at https://doi.org/10.1007/ s00432-019-02881-8.

Berardino De Bari

bdebari@chu-besancon.fr

Alessandra Franzetti-Pellanda

Alessandra.Franzetti-Pellanda@moncucco.ch

Asma Saidi

asma.saidi@gmail.com

Maira Biggiogero

maira.biggiogero@clinicaluganese.ch

Dieter Hahnloser

Dieter.Hahnloser@chuv.ch

Michael Montemurro

Michael.Montemurro@chuv.ch

Jean Bourhis

Jean.Bourhis@chuv.ch

Michele Zeverino

Michele.Zeverino@chuv.ch which permits use, duplication, adaptation, distribution and reproduction in any medium or format, as long as you give appropriate credit to the original author(s) and the source, provide a link to the Creative Commons license and indicate if changes were made.

The original article has been corrected.

Open Access This article is distributed under the terms of the Creative Commons Attribution 4.0 International License (http://creativeco mmons.org/licenses/by/4.0/), which permits unrestricted use, distribution, and reproduction in any medium, provided you give appropriate credit to the original author(s) and the source, provide a link to the Creative Commons license, and indicate if changes were made.

Publisher's Note Springer Nature remains neutral with regard to jurisdictional claims in published maps and institutional affiliations.

Mahmut Ozsahin

mahmut.ozsahin@chuv.ch

1 Radiation Oncology Department, Centre Hospitalier Universitaire Vaudois, CHUV, 46 rue du Bugnon, 1011 Lausanne, Switzerland

2 Radiation Oncology Department, Centre Hospitalier Régional Universitaire Jean Minjoz, INSERM U1098 EFS/BFC, Besançon, France

3 Radiation Oncology Department, Clinica Luganese, 6900 Lugano, Switzerland

4 Surgery Department, Centre Hospitalier Universitaire Vaudois, 1011 Lausanne, Switzerland

5 Medical Oncology Department, Centre Hospitalier Universitaire Vaudois, 1011 Lausanne, Switzerland

6 Medical Physics Department, Centre Hospitalier Universitaire Vaudois, 1011 Lausanne, Switzerland 